\title{
Geochemical behavior of hafnium in the Amazon River estuary and its flux to the Atlantic
}

\author{
ANTAO XU ${ }^{1 *}$, EDMUND HATHORNE ${ }^{1}$, MARTIN FrANK ${ }^{1}$ \\ ${ }^{1}$ GEOMAR Helmholtz Centre for Ocean Research Kiel, \\ Wischhofstrasse 1-3, Kiel 24148, Germany \\ (*correspondence: axu@geomar.de)
}

Combined measurements of radiogenic hafnium (Hf) and neodymium $(\mathrm{Nd})$ isotopes have been demonstrated to be a valuable tracer of continental weathering regimes and water mass mixing on short spatial scales $[1,2]$. While there is information on inputs of REEs via major rivers such as the Amazon [3], little is known about the estuarine behavior of Hf and the impact of the Amazon on the Atlantic Hf budget [4]. We therefore measured dissolved $\mathrm{Hf}$ concentrations of estuarine waters along the entire salinity gradient of two transects in the Amazon River estuary obtained during RV Meteor cruise M147, which was official process study GApr11 of the international GEOTRACES program.

Our results demonstrate strong removal of dissolved $\mathrm{Hf}$ in the low-salinity waters of the estuary likely caused by saltinduced coagulation while some release of $\mathrm{Hf}$ from particles may occur in the mid- to high-salinity range, similar to the observations for $\mathrm{Nd}$ in the Amazon River estuary [e.g. 3]. In the $0-10$ salinity range, $76 \%$ to $86 \%$ of the dissolved riverine Hf were removed from solution. The dissolved Hf flux of the Amazon River to the Atlantic is thus calculated to be $26.5 \mathrm{x}$ $10^{3} \mathrm{~mol} / \mathrm{yr}$ based on an average of $19 \%$ of the total riverine $\mathrm{Hf}$ being transported into the Atlantic. Furthermore, we roughly estimate that a Hf flux of at least $7.9 \times 10^{3} \mathrm{~mol} / \mathrm{yr}$ is released from suspended particulate matter (SPM) or bottom sediment in the mid- to high-salinity zone based on a $\mathrm{Hf}_{\mathrm{SPM}}$ concentration of $3.3 \mathrm{mg} / \mathrm{kg}$ [4] and Amazon sediment discharge of $7.5 \times 10^{8} \mathrm{t} / \mathrm{yr}$ [5]. Our results thus support that the Amazon River contributes significantly to the Atlantic's Hf budget and that estuarine processes control the riverine Hf flux to the ocean. Combining these data with $\mathrm{Hf}$ isotope compositions of the same samples will allow the Amazon's impact on the Atlantic $\mathrm{Hf}$ isotope budget to be constrained.

[1] Frank et al. (2002) Rev. Geophys. 40, 1001. [2] Filippova et al. (2017) GCA 199, 164-184. [3] Rousseau et al. (2015) Nat. Comm. 6, 7592. [4] Merschel et al. (2017) GCA 213, 383-399. [5] Martinez et al. (2009) Catena 79, 257-264. 